Entre sus efectos adversos principales, destaca la posibilidad de aparición de sofocos, pérdidas vaginales, incremento del riesgo de fenómenos tromboembólicos y de neoplasias de endometrio, ésta última sobre todo cuando el periodo de administración del fármaco es de varios años (2).

Se han descrito muy pocos casos de hiperlipidemias inducidas por la administración de tamoxifeno (3-5); recientemente hemos tenido ocasión de diagnosticar un nuevo caso y nos parece interesante comentarlo brevemente.

Mujer de 44 años de edad, sin antecedentes personales de interés. Hace 11 meses consultó tras denotar la aparición de una tumoración en la mama derecha de unos 2-3 centímetros de diámetro. Tras realizar los estudios correspondientes, fue intervenida realizándose cuadrantectomía y linfadenectomía. La histología fue de carcinoma ductal infiltrante grado I de Bloom y Richardson; existían metástasis ganglionares en uno de 12 ganglios extirpados. Los receptores de estrógenos y progesterona fueron positivos y el p53 y el cerbB2 eran negativos.

Los estudios de extensión realizados, mediante una ecografía hepática y una gammagrafía ósea fueron normales, por lo que fue clasificada como carcinoma de mama estadio IIB.

Se decidió realizar tratamiento de poliquimioterapia con esquema FEC (5-fluorouracilo-epirubicina y ciclofosfamida), por seis ciclos, seguido de radioterapia y braquiterapia y posteriormente hormonoterapia con tamoxifeno por un período previsible de 5 años.

Previamente a la cirugía en un control bioquímico el colesterol era de $205 \mathrm{mg} / \mathrm{dl}$ y los triglicéridos de $64 \mathrm{mg} / \mathrm{dl}$. Tras completar la quimioterapia y la radioterapia en una nueva analítica el colesterol era de $212 \mathrm{mg} / \mathrm{dl}$ y los triglicéridos de $52 \mathrm{mg} / \mathrm{dl}$.

A los 3 meses de iniciada la hormonoterapia con 20 miligramos al día de tamoxifeno, en un control bioquímico el colesterol era de $439 \mathrm{mg} / \mathrm{dl}$ y los triglicéridos de 331 miligramos/dl. Tras repetir el estudio analítico se confirmó una cifra de colesterol de $430 \mathrm{mg} / \mathrm{dl}$, con una fracción HDL de $73 \mathrm{mg} / \mathrm{dl}$ y una LDL de 333 $\mathrm{mg} / \mathrm{dl}$, los triglicéridos eran de $310 \mathrm{mg} / \mathrm{dl}$.

Tras suspender el tamoxifeno, a las tres semanas el colesterol fue de $301 \mathrm{mg} / \mathrm{dl}$ y los triglicéridos de $130 \mathrm{mg} / \mathrm{dl}$ y en una nueva analítica a las seis semanas, el colesterol era de $188 \mathrm{mg} / \mathrm{dl}$ y los triglicéridos de $109 \mathrm{mg} / \mathrm{dl}$.

No se realizó ninguna modificación con respecto a la dieta de la enferma y tampoco se añadió tratamiento hipolipemiante alguno.

Entonces se añadió como terapia hormonal adyuvante, anastrozol.

En un nuevo control bioquímico realizado a las seis semanas de iniciarse el nuevo tratamiento, los niveles de colesterol y triglicéridos eran normales.

Habitualmente el tamoxifeno induce un efecto favorable sobre los lípidos, disminuyendo el nivel de colesterol LDL, aunque puede provocar un pequeño incremento del nivel de triglicéridos. Esta elevación, no suele ser muy relevante, siendo muy pocos frecuentes los casos descritos de severa hipertrigliceridemia y pancreatitis secundarios a la administración de tamoxifeno $(4,5)$.

La actividad de las enzimas lipolíticas se encuentran reducidas durante el tratamiento con tamoxifeno, debido a su efecto estrogénico $(2,4)$.

Generalmente las alteraciones lipídicas regresan tras la suspensión del tratamiento con tamoxifeno, aunque en ocasiones es preciso añadir tratamiento con fármacos hipolipemiantes, fundamentalmente fibratos (5).

Por todo lo referido, es necesario vigilar los niveles de colesterol y triglicéridos en el curso del tratamiento con tamoxifeno, para detectar precozmente alteraciones en el perfil lipídico, que en ocasiones pueden originar patologías severas, como la pancreatitis.

F. Marcos Sánchez, A. Viana Alonso, D. Marrupe González, M. I. Albo Castaño, F. Juárez Ucelay
Servicio de Medicina Interna-Oncología. Hospital Nuestra Señora del Prado. Talavera de la Reina. Toledo

1. Glick JH, Gelbert RD, Goldhirsch A. Senn HJ. Adjuvant therapy of primary breast cancer. Ann Oncol 1992; 3: 801-807.

2. Barnadas A. Cáncer de mama (II): Estrategias terapéuticas. Oncología médica de Rosell R, Abad A, Monzo M, Molina F. Ediciones Ergon SA. Madrid 1995; 197-209.

3. Hozumi Y, Kawano M, Miyata M. Severe hypertriglyceridemia caused by tamoxifen-treatment breast cancer surgery. Endocrinol J 1997; 44: 745-749.

4. Elisaf MS, Nakou K, Liamis G, Pavlidis NA. Tamoxifen-induced severe hypertriglyceridemia and pancreatitis. Ann Oncol 2000; 11: 1067-1069.

5. Colls BM, George PM. Severe hipertriglyceridemia and hypercholesterolaemia associated with tamoxifen use. Clin Oncol 1998; 10: 270-271.

\section{Meningoencefalitis por virus herpes tipo 6 en paciente anciano con Alzheimer}

\section{Sr. Director:}

El herpes virus humano tipo 6 (HVH-6) agente causal de la roseola infantil en la infancia, convulsiones febriles, meningitis y encefalitis son complicaciones de esta enfermedad (1). En pacientes inmunodeprimidos pueden infectarse con este virus y coexistir infecciones como el citomegalovirus, observándose infecciones frecuentes en transplantes de médula ósea y de hígado (2). Para el diagnóstico existen tests serológicos y se puede detectar el genoma del virus por PCR en diferentes tejidos (3). El HVH-6 tiene dos variantes el tipo $\mathrm{B}$ que se asocia a enfermedad febriles en los niños y predomina en sanos y el tipo A menos prevalerte se ha implicado en reactivación en inmunocompetentes con enfermedades graves y se ha relacionado con esclerosis múltiple (4).

Paciente mujer de 88 años ingresa por deterioro del nivel de conciencia de tres días de evolución. Antecedentes de cardiopatía hipertensiva en fibrilación auricular. Demencia de Alhzeimer estudiada en neurología hacía año y medio con dependencia total para la vida diaria. Sigue tratamiento con anticoagulantes orales y digoxina. Presentaba desconexión del medio sin fiebre y sin convulsiones previas. La exploración neurológica era normal salvo el estado de conciencia sin signos meningeos y afebril. En la exploración cardiopulmonar destacaba arritmia cardíaca a 80 latidos sin soplos. En la analítica $17 \mathrm{Hb} 50 \mathrm{Hto}, 25.300$ leucocitos con $90 \%$ de neutrófilos, 234.000 plaquetas, TP 34\%, INR 3,14, glucosa 150 , urea 118 , creatinina 1,2 . Na 145 , K 4,4, orina normal. ECG fibrilación auricular a 80 latidos por minuto. Bloqueo de rama izquierda del Haz de Hiss. Rx de tórax: cardiomegalia, sin patología aguda pleuropulmonar. Hemocultivos negativos. TAC craneal de urgencias: Atrofia cortico-subcortical RMN cerebral: Atrofia cerebral moderada. LCR (tras corrección de la coagulación): 45 células con $60 \%$ de monomorfonucleares. Glucosa $101 \mathrm{mg} / \mathrm{dl}$, proteínas $50 \mathrm{mg} / \mathrm{dl}$, ADA 5,4. tinción de Gram de liquido: no se observan gérmenes. Cultivos de LCR para bacterias, hongos y micobacterias negativos. VIH: negativo. Se envió LCR al Centro Nacional de Microbiología de Majadahonda donde en el estudio de PCR del líquido detecta virus herpes humano tipo 6. La paciente fue tratada con ampicilina, ceftriaxona hasta que se recibieron los cultivos negativos. Además fue tratada con aciclovir a dosis de $10 \mathrm{mg} / \mathrm{kilo} / 8$ horas durante 15 días. La enferma mejoró parcialmente pudiendo alimentarse por vía oral y falleció en su domicilio a los 3 meses probablemente de una broncoaspiración. 
Hay pocos casos en la literatura descritos de meningoencefalitis por HVH tipo 6 en el adulto inmunocompetente (aunque realmente nuestra enferma tenia la inmunodeficiencia propia de la edad. La seropositividad del herpes 6 se ve incrementada con la edad. Se postula que el SNC puede ser el lugar de persistencia del HVH tipo 6 como estado latente tras la resolución de la primoinfección (4). Los casos descritos en inmunocompetentes es variable con respecto a su evolución. Así, Córdoba López et al (5) describe un caso fatal en un paciente de 29 años inmunocompetente con fallo multiorgánico y muerte (no fue tratado con aciclovir). Losada et al (6) describen una evolución favorable en un paciente de 18 años que fue tratado con aciclovir. Torre et al (7). También describe una buena evolución en un paciente de 59 años tratado con aciclovir, resolviéndose la clínica del enfermo en pocos días. Dado que el aciclovir tiene muy poca actividad in vitro frente al HVH tipo 6 (sería a dosis muy elevadas). Siendo el foscarnet efectivo frente al VHH 6 tipo A y tipo B y el ganciclovir actúa solo frente al tipo B (ya que han sido descritas resistencias frente al A) (8). Probablemente en virtud de los casos descritos, es posible cierta actividad in vivo del aciclovir en la meningoencefalitis por HVH-6 en personas inmunocompetentes. De todas formas se necesitan estudios amplios para verificar la sensibilidad in vivo de estos fármacos en la meningoencefalitis por HVH tipo 6.

\section{Cutrín Prieto, A. Batalla Eiras, M. Pato Salgado}

\section{Servicio de Medicina Interna. Complexo Hospitalario. Ourense}

1. Asano Y, Hoshikawa T, Suga S, et al. Clinical features of infants with primary human herpes virus 6 infection (exanthem subitum, roseola infantum). Pediatric 1999; 83: 104.

2. Singh N, Paterson DL. Encephalitis caused by human herpes virus 6 in transplants recipients. Relevance of a novel neurotropic virus. Transplantation 2000; 69: 2474

3. Norton RA, Caserta MT, Hall CB, et al. Detection of human herpes virus 6 by reverse transcription-PCR. J Clin Microbiol 1999; 37: 3672.

4. Clark DA: Human herpes virus 6. Rev Med Virol 2000; 10: 155-73.

5. Córdoba López I, Bueno Alvarez-Arenas J, et al. Meningoencefalitis por virus herpes simple tipo 6 en adulto inmunocompetente An Med Interna (Madrid) 2004; 4: 201

6. Losada I, Pozo F, Tenorio A, et al. Meningoencefalitis causada por el VHH- $6^{a}$ en un adulto inmunocompetente previamente sano. Med Clin (Barc) 2003; 120: 357

7. D Torre F, Speranza R, Martegani P, et al. Meningoencefalitis caused by human herpes virus 6 in an inmunocompetent adult patient: Case report and review of liter.ature. Infection 1998; 26: 402-404.

8. Williams MU.HHV-6 response to antiviral agents, In: Human herpes virus 6: Epidemiology, molecular biology and clinical pathology. Ablashi DV, Krueger RF and Salahuddin SZ (Eds). Elsevier Biomedical Press, Amsterdam, The Netherlands p. 317

\section{Dermatomiositis en una paciente con artritis reumatoide tratada con leflunomida}

\section{Sr. Director:}

La leflunomida es un derivado isoxazólico que, una vez absorbido, se transforma en el compuesto activo A77-1726, que inhibe la dihidro-oroato-deshidrogenasa en las células activadas, interfiriendo con la síntesis de pirimidinas y estabilizando el ciclo celular de los linfocitos $\mathrm{T}$ en la fase G1, por lo que se comporta como un fármaco inmunomodulador y se clasifica entre los fármacos antirreumáticos de acción lenta (FARAL). Está indicada para el tratamiento de la artritis reumatoide, en la que desarrolla su actividad clínica trascurridas unas cuatro semanas y estabiliza su acción a partir de la vigésima semana (1-3). Es teratógena y casi la mitad de los pacientes tratados experimentan algún efecto adverso, destacando los trastornos gastrointestinales (diarrea, dolor abdominal, náuseas), la elevación de las enzimas hepáticas, el aumento de la presión arterial y las erupciones cutáneas. Muy rara vez se ha descrito eritema multiforme e incluso un síndrome de Stevens-Johnson. Frente a otros FARAL como la D-penicilamina o la salazopirina, que pueden asociarse a la aparición de una dermatomiositis o lupus inducido (4-6), con la leflunomida, en nuestro conocimiento, no se ha reportado este tipo de enfermedades autoinmunes. Por este motivo, consideramos de interés la comunicación del caso de una paciente que presentó una dermatomiositis tras la administración de leflunomida y que evolucionó favorablemente tras la suspensión de ésta.

Paciente de 45 años que consultó por presentar, desde hacía seis meses, astenia, pérdida de peso, debilidad muscular y tumefacción dolorosa difusa en las manos y en los párpados. A los 35 años había sido diagnosticada de artritis reumatoide a causa de una poliartritis seropositiva crónica y simétrica con afectación predominante de las pequeñas articulaciones de manos y pies, asociada a rigidez matutina de más de una hora de duración y osteoporosis yuxtarticular. El tratamiento inicial con aurotiomalato sódico había sido interrumpido a causa de una dermatitis exfoliativa. A lo largo de los primeros cinco años de la enfermedad, de forma secuencial, se habían introducido salazopirina, metotrexato oral y cloroquina. Todos se mantuvieron por periodos inferiores a seis meses a causa de efectos adversos gastrointestinales. La dificultad para controlar satisfactoriamente la artritis reumatoide con antiinflamatorios no esteroideos y bajas dosis de prednisona llevó a introducir leflunomida en abril de 2002. A partir de la tercera semana de haber iniciado dicho fármaco, de forma gradual, se instauraron los síntomas que motivaron la consulta en nuestra unidad de reumatología.

En la exploración destacaban: peso $(52 \mathrm{~kg})$, talla $(168 \mathrm{~cm})$, poliartritis afectando las metacarpofalángicas, interfalángicas proximales, rodillas, tobillos y codos, lesiones eritematosas sobreelevadas en la superficie extensora de dichas articulaciones, eritema violáceo y edema palpebral (Fig. 1), eritema periungueal, alopecia activa, xerostomía y debilidad muscular proximal (4/5). La auscultación cardiopulmonar era normal, no se palpaban organomegalias y, excepto la debilidad y atrofia muscular de predominio proximal, en la exploración neurológica no se apreciaron otras alteraciones.

Laboratorio: anemia normocrómica normocítica (hemoglobina de $107 \mathrm{~g} / \mathrm{L})$, leucocitos: $4,8 \times 10^{9} / \mathrm{L}, \mathrm{VSG}\left(56 \mathrm{~mm} / 1^{\mathrm{a}} \mathrm{h}\right)$, Proteína C Reactiva $(69 \mathrm{mg} / \mathrm{L})$, factor reumatoide (látex): $174 \mathrm{UI} /$ $\mathrm{ml}$; las siguientes determinaciones fueron normales: glucosa, triglicéridos, colesterol total, ASAT, ALAT, GGT, FA, creatinina, urea, $\mathrm{CK}, \mathrm{Ca}, \mathrm{P}, \mathrm{Na}, \mathrm{K}, \mathrm{Cl}$, dosificación del complemento (CH50, C3, C4), hormonas tiroideas e inmunoglobulinas ( $\operatorname{IgM}$, IgG, $\operatorname{IgA}, \operatorname{IgE}$ ) así como análisis de orina. Los siguientes autoanticuerpos fueron negativos: ANA, anti-DNA, anti-ENA, antiRNP, anti-Jo1, anti-PL7 y anti-PL12, anti-Mi2, anticuerpos antifosfolipídicos y ANCA. Las serologías para citomegalovirus y toxoplasma fueron negativas para infección reciente. La radiografía de tórax fue normal y las radiografías de manos y pies mostraron una intensa osteopenia yuxtarticular y algunas erosiones en las metacarpofalángicas y los carpos. El estudio electromiográfico demostró potenciales polifásicos, disgregación de la actividad eléctrica y disminución de amplitud y duración de los potenciales de unidad motora. Se hizo una biopsia de piel en la que no se apreció depósito de inmunoglobulinas ni complemento en la unión dermoepidérmica, aunque sí infiltrados linfocitarios perivasculares aislados.

Se suspendió leflunomida y se administró colestiramina así como azatioprina (100 mg/día) y prednisona (30 mg/día). Ésta se redujo gradualmente a lo largo de las siguientes ocho semanas, 